\title{
ARTICULAÇÕES ENTRE EDUCAÇÃO MATEMÁTICA, BRINCADEIRAS E CORPO EM MOVIMENTO NA EDUCAÇÃO INFANTIL NA PERSPECTIVA DA COMPLEXIDADE
}

\author{
ARTICULATIONS BETWEEN MATHEMATICAL EDUCATION, PLAY AND \\ BODY IN MOVEMENT IN EARLY CHILDHOOD EDUCATION FROM THE \\ PERSPECTIVE OF COMPLEXITY
}
Paulo Robson Duarte Barbosa
Rede Municipal de Curitiba paulorob84@hotmail.com

Ettiène Guérios

Universidade Federal do Paraná - UFPR

ettiene@ufpr.br

\begin{abstract}
Resumo
Este artigo tem como eixo norteador a Educação Matemática na Educação Infantil a partir do intercâmbio entre dois campos de experiências: "espaços, tempos, quantidades, relações e transformações" e "corpo, gestos e movimentos", conforme documento normativo que orienta as práticas pedagógicas em território nacional, a Base Nacional Comum Curricular (BNCC). O objetivo do estudo concentra-se na análise da percepção de conhecimentos matemáticos em brincadeiras que envolvem o corpo em movimento por parte dos professores de Educação Infantil. A pesquisa de abordagem qualitativa e natureza exploratório-interpretativa reuniu como instrumentos de produção de dados questionário e roda de conversa com três professoras da Educação Infantil. A análise revela que as profissionais percebem a importância das brincadeiras que envolvem o corpo em movimento para formação de conhecimentos matemáticos na primeira infância. No entanto, reconhecem fragilidades conceituais em decorrência de precariedade na formação inicial. Os resultados permitem refletir sobre a relevância da Educação Matemática na Educação Infantil por meio das brincadeiras, evidenciando o corpo em movimento como alicerce para o desenvolvimento infantil.

Palavras-chave: Primeira infância. Educação Infantil. Conhecimentos matemáticos. Práticas pedagógicas. Educação Matemática.
\end{abstract}

\begin{abstract}
This article has as its guiding principle the Mathematical Education in Early Childhood Education through the exchange between two fields of experiences: "spaces, moments, quantities and transformations" and "bodies, gestures and movements", according to the normative document that guides the pedagogical practices in national territory, the National Common Curricular Base (BNCC). The aim of this study is focused on the analysis of the perception of mathematical knowledge in games involving the body in motion by the teachers of Early Childhood Education. The research with a qualitative approach and exploratory-interpretative
\end{abstract}


nature brought together questionnaire and conversation circles with three teachers of Early Childhood Education as instruments of data production. The analysis reveals that the professionals realize the importance of games that involve the body in movement for the formation of mathematical knowledge in early childhood. However, they recognize the conceptual fragilities weaknesses as a result of precariousness in initial training. The results allow a reflection about the relevance of Mathematics Education in Early Childhood Education through play, showing the body in motion as a foundation for child development.

Keywords: Early childhood. Early childhood education. Mathematical knowledge. Pedagogical practices. Mathematical Education.

\section{INTRODUÇÃO}

Este artigo evidencia a relevância de práticas pedagógicas na Educação Infantil em diálogo com a teoria da complexidade, sob a perspectiva do pensamento complexo, ao se inspirar nas considerações acerca da Educação postuladas por Morin (2000, 2005, 2011, 2015). Com origem na investigação de Barbosa (2020), seu eixo central é a discussão a respeito da Educação Matemática na Educação Infantil, tendo como fulcro o intercâmbio entre dois campos de experiências: o primeiro, relacionado a espaços, tempos, quantidades, relações e transformações, e o segundo, a corpo, gestos e movimentos. Ambos fundamentados no documento normativo que orienta as práticas pedagógicas em território nacional, a Base Nacional Comum Curricular (BNCC) (BRASIL, 2017).

O intercâmbio entre esses campos operacionaliza a leitura multirreferencial, multifacetada e multidimensional do fazer pedagógico na Educação Infantil, uma vez que estabelece relações entre saberes diversos, valoriza experiências que compõem um efeito multifacetado e amplo por contemplar a multiplicidade, proporciona conexões e comunicações policompetentes, promove noções que se solidarizam e se complementam e ainda contextualiza o movimento corporal infantil aos conhecimentos matemáticos.

Essas reflexões destacam a interação e a organização das ações didáticas por meio de brincadeiras que envolvem o corpo em movimento e a Matemática, tendo em vista que a prática educacional do ensino dessa ciência pode ser mais significativa às crianças. Todavia, algumas questões emergem para uma efetiva reflexão: existe uma preocupação com o movimento corporal infantil no que tange à sua atuação articulada com os conhecimentos matemáticos na primeira infância? Como estão organizadas as práticas de movimento corporal relacionadas à Educação Matemática nas escolas de Educação Infantil? Que atividades associadas ao movimento do corpo infantil e aos conhecimentos matemáticos estão materializadas no contexto escolar? 
Em busca de respostas, este estudo visa à análise da percepção dos professores de Educação Infantil referentemente aos conhecimentos matemáticos presentes em brincadeiras que envolvem o corpo em movimento. Sob essa premissa, o foco de discussão se volta ao docente da Educação Infantil, com atenção especial às práticas metodológicas e ações didáticas.

O artigo resulta de uma pesquisa que se estrutura na tríade Educação Matemáticabrincadeiras-corpo em movimento, elementos que se articulam entre si e compõem um sistema que possibilita a interpretação de dados. Por intermédio da integração entre esses componentes é que se estabelecem, portanto, os conceitos como um sistema vivo, e não a partir dos conceitos isolados de corpo, movimento, brincadeira e Matemática. Essa concepção vai ao encontro dos ensinamentos de Morin (2005), ao afirmar que a complexidade quebra esferas fechadas e estabelece articulações para a constituição da multidimensionalidade e das totalidades integradoras. Logo, esta ideia configura a base da tríade em pauta.

Dessa tríade emergem considerações que são discutidas e amparadas pela literatura da Educação Matemática na Educação Infantil e por concepções advindas da Educação Física acerca do corpo em movimento. A abordagem teórica que fundamenta as relações determinadas no interior da tríade tem como alicerce, prioritariamente, os estudos de: Kamii (1984, 1991,1995, 2002, 2005, 2009); Smole, Diniz e Cândido (2000); Duhalde Cuberes (1998); Da Costa et al. (2018); Gallahue e Ozmun (2005); Le Boulch (1982, 1983); Freire (1989); Guedes (1998); Garanhani (2004, 2005), além da BNCC (BRASIL, 2017).

Sob essa ótica e com o intento de colocar em evidência as contribuições das brincadeiras que envolvem o corpo em movimento para a apropriação e formação dos conhecimentos matemáticos na Educação Infantil, espera-se que este artigo possa fortalecer ainda mais o debate em torno da tríade.

\section{REFERENCIAL TEÓRICO}

A reflexão sobre o corpo em movimento relacionado aos conhecimentos matemáticos na Educação Infantil é discutida na literatura da Matemática com base em brincadeiras, jogos, atividades psicomotoras, atividades rítmicas e expressivas, danças, músicas e histórias cantadas. Desse universo lúdico, são apresentadas fundamentações e orientações que avalizam a relação Matemática-corpo em movimento. Isso se justifica pelo fato de que os conhecimentos matemáticos e as atividades motoras estão presentes 
desde os primeiros momentos da vida da criança. Na Educação Infantil, a gama de atividades que envolve o corpo em movimento proporciona um cenário propício para o desenvolvimento dos conhecimentos aritméticos, algébricos e geométricos.

Ao considerar a aritmética na Educação Infantil e nos Anos Iniciais do Ensino Fundamental como campo de pesquisa, Kamii (1984, 1991, 1995, 2002, 2005, 2009) apontam que as atividades de lançar, arremessar e rebater, as brincadeiras de perseguição, de descobertas e de alvo, assim como as corridas e as brincadeiras de pegar e de esconder, podem envolver quantificação e ordenação de objetos. Para os estudiosos, isso significa uma possibilidade de encorajar a criança a: pensar sobre o número e quantidades de objetos; manter-se alerta e colocar todos os tipos de objetos, eventos e ações em todas as espécies de relações; quantificar objetos logicamente e comparar conjuntos; fazer conjuntos com objetos móveis; trocar ideias com seus colegas.

Segundo Kamii (2009), o termo "encorajar" representa a perspectiva do ensino indireto em se tratando de implicações pedagógicas no âmbito da ideia de número, uma vez que "aritmética não vem de livros, explicações das professoras ou programas de computador, mas de cada pensamento da criança à medida que ela aritmetiza logicamente sua realidade" (p. 168). Nessa perspectiva, o pensamento numérico e suas relações são construídos a partir das associações que as crianças criam quando são encorajadas a pensar.

Em uma Educação focada na autonomia, como salienta Kamii (1984, 1991,1995, 2002, 2005, 2009), o conhecimento é construído ativamente pela criança. Para tanto, qualidades como curiosidade, iniciativa, agilidade mental e pensamento crítico são essenciais. Nesse sentido, quando age com liberdade e iniciativa própria, a criança se torna capaz de levantar hipóteses, aventar possibilidades, encontrar soluções, descobrir respostas, analisar decisões, construir critérios, apresentar argumentos e pensar criticamente. Dessa forma, ela produz tomadas de consciência e desenvolve o nível de compreensão das ações realizadas.

Freire (1989), em uma de suas abordagens sobre uma educação de corpo inteiro, declara que, no período da Educação Infantil, o pensamento e o corpo precisam ser exercitados. $\mathrm{O}$ autor ressalta que é nessa fase de escolarização que se constituem as bases fundamentais das habilidades cognitivas, por isso é necessário aprender a pensar.

Para Freire (1989), as noções de tempo, espaço e características físicas dos objetos "podem ser desenvolvidas num corpo em movimento, que corre, que pula, que brinca" (p. 39). Assim sendo, chegar às noções lógicas de classificação, seriação e 
conservação é perfeitamente possível à criança, pois "a criança que brinca em liberdade, podendo decidir sobre o uso de seus recursos cognitivos para resolver problemas, sem dúvida alguma chegará ao pensamento lógico de que necessita a ler, escrever e contar" (p. 39).

O movimento corporal infantil, como evidencia Garanhani (2005), é uma forma utilizada pela criança para conhecer a si própria e o meio em que está inserida, expressar seu pensamento, interagir com o mundo que a cerca, como também experimentar relações com pessoas e objetos. Por conseguinte, a educação do corpo em movimento na Educação Infantil contribui consideravelmente para o desenvolvimento das potencialidades das crianças e à apropriação dos saberes escolares.

\footnotetext{
Na pequena infância, o corpo em movimento constitui a matriz básica, em que se desenvolvem as significações do aprender, devido ao fato de que a criança transforma em símbolo aquilo que pode experimentar corporalmente e seu pensamento se constrói, primeiramente sob a forma de ação (GARANHANI, 2005, p. 89).
}

À vista disso, compreende-se, que por meio da linguagem simbólica e cinestésica, a criança percebe, reflete, relaciona, articula, conhece, pensa e, sobretudo, aprende. Desse modo, é imprescindível desenvolver na criança a possibilidade de representação mental e, progressivamente, a possibilidade de representação com os números e suas múltiplas formas de relação. Isso porque ordenar, seriar, classificar, contar e numerar constituem fundamentalmente ações de brincar com os objetos. Tais ações permitem à criança separar, juntar, estabelecer correspondência e relações, fazer arranjos e combinações, categorizar, distinguir, dividir, conceituar, sequenciar, reunir, comparar, representar, selecionar, organizar, agrupar, caracterizar e classificar cada um dos objetos que toca ou manipula no seu cotidiano escolar.

Guedes (1998) corrobora com essa forma de aprendizagem ao enfatizar que brincadeiras recreativas que exigem a movimentação do corpo são importantes para o aprimoramento da consciência corporal e para o desenvolvimento do aprender a pensar para agir. Partindo do pressuposto de que, ao brincar, a criança se comunica corporal e verbalmente, infere-se que o desenvolvimento de brincadeiras que envolvem o corpo em movimento promove a percepção de como a criança interpreta, articula e soluciona desafios propostos, bem como a observação das noções ou ideias matemáticas que ela forma enquanto age e interage com os outros.

O desenvolvimento do pensamento algébrico tem suas raízes na Educação Infantil. As habilidades de pensar analiticamente, generalizar, perceber regularidades e 
abstrair relações, regras e estruturas, são intrínsecas à atividade matemática e ao pensamento algébrico. Tais habilidades constituem, portanto, as primeiras aproximações com os conhecimentos algébricos, os quais se estruturam em ideias de generalização e de formalização na Educação Infantil.

Em conformidade com Nacarato e Custódio (2018), desde pequena, a criança consegue perceber semelhanças e diferenças entre objetos, bem como abstrair suas características e perceber regularidades. Uma atividade que exemplifica essas habilidades é a criação de uma sequência que siga um determinado padrão, pois, além de criar a sequência, a criança se vê no movimento de garantir que ela siga um padrão lógico e compreensível.

Vale ressaltar que pensar algebricamente na Educação Infantil não configura uma mera reprodução e repetição de técnicas, mas sim, a percepção e a generalização de regularidades. Logo, propostas que ativam a imaginação são basilares e indispensáveis, pois viabilizam a elaboração de hipóteses e de conjecturas que constituirão possíveis generalizações (NACARATO; CUSTÓDIO, 2018).

Camargo et al. (2018) salientam que as propostas de trabalho que envolvem o pensamento algébrico devem priorizar o lúdico, a imaginação e o corpo como um todo na Educação Infantil. Além disso, asseveram que “o desenvolvimento do pensamento algébrico na Educação Infantil pressupõe o processo de vivenciar o padrão com ênfase em propostas que promovam o movimento do corpo" (p. 34). As autoras também sustentam a ideia de que "A criança é movimento, e, à medida que brinca e se movimenta, recria e repensa os acontecimentos à sua volta, e desenvolve a prática do respeito ao outro, da ética, além de habilidades cognitivas e motoras" (p. 30).

Nesse contexto, danças, músicas, histórias cantadas, atividades manipulativas e brincadeiras que trazem regularidades de movimentos do corpo ou da letra da música a ser cantada são estratégias que levam a criança a "perceber a regularidade dos movimentos da dança e de brincadeiras; perceber e continuar um motivo de repetição ou de crescimento; perceber e repetir uma sequência de gestos ou de movimentos corporais" (CAMARGO et al. 2018, p. 34).

\section{O QUE DIZEM AS PESQUISAS}

O levantamento de pesquisas stricto senso relacionadas às brincadeiras que envolvem o movimento do corpo com a Matemática na Educação Infantil, realizado nas plataformas on-line de pesquisa CAPES e IBCT, no período de 2016 a 2020, resultou em 
uma tese e três dissertações. Em seus estudos, Zogaib (2019), Silva (2016), Cavalcante (2015) e Oliveira (2017) fazem ponderações, relatam experiências e apresentam reflexões e aprofundamentos teóricos a respeito das brincadeiras relacionadas à Matemática na Educação Infantil.

Zogaib (2019) destaca que, em meio às brincadeiras, os movimentos e as falas das crianças demonstravam ideias de localização, posição e direção, com indicações de relações espaciais vivenciadas por elas. Silva (2016) aponta, em suas análises, a pertinência e a importância da brincadeira nessa fase de escolarização e a relevância do movimento das crianças para solucionar questões espaciais. Cavalcante (2015) sinaliza que as situações emergentes do cotidiano aproximam as crianças por meio de brincadeiras e defende que, para as mais variadas noções matemáticas, essa é a atividade principal das crianças pré-escolares. Complementarmente, Oliveira (2017) ressalta: "Frequentar a Educação Infantil é ir além de momentos de convivência. É ter acesso a uma gama de oportunidades de se desenvolverem por meio de ações lúdicas e com intervenções pedagógicas, habilidades que as auxiliem na elaboração de conceitos matemáticos" (p. 138).

Da Costa et al. (2018) apresentam atividades matemáticas que exploram o corpo e brincadeiras que envolvem o corpo em movimento, contemplando conteúdos específicos, tais como: percepção visual; posição e localização no espaço; organização e posição no espaço; exploração corporal e do espaço; deslocamento no espaço; noções de perto/longe, esquerda/direita, para frente/para trás; sólidos geométricos e figuras planas. Além desses, muitos outros conteúdos que desenvolvem as noções espaciais podem ser abordados, conforme explicitam as autoras:

\footnotetext{
Para que a criança desenvolva seu conhecimento sobre tais noções é necessário, no entanto, que lhe sejam proporcionadas atividades e situações nas quais ela possa agir sobre o meio explorando-o a partir do seu corpo, isto é, devem ser criadas condições para que a criança construa e coordene seu espaço com base em seus esquemas motores. Desse modo, é imprescindível que o professor/educador organize o ambiente, criando situações interessantes e desafiadoras com materiais diversos em espaços diferentes, nos quais a criança possa, a partir de brincadeiras e/ou jogos, ser estimulada a desenvolver essas noções (DA COSTA et al., 2018, p. 86).
}

Enquanto se movimentam, as crianças desenvolvem relações espaciais, visto que “o corpo é o primeiro espaço que a criança conhece e reconhece e as explorações do espaço externo a ela própria são primeiramente feitas a partir do corpo" (SMOLE; DINIZ; CANDIDO, 2000, p. 15). Dessa forma, as brincadeiras que envolvem o corpo em movimento, bem como as atividades de deslocamentos, orientações e localização 
espacial, ampliam noções como proximidade, separação, vizinhança, continuidade, distância, direção, sentido, ponto de referência, amplitude de giro, dentre outras.

Ao tecer reflexões sobre conhecimentos matemáticos e movimento corporal na Educação Infantil, identifica-se que as concepções de práticas pedagógicas de corpo em movimento contribuem substancialmente para esse diálogo. Assim sendo, o movimento corporal infantil contribui de modo significativo para a apropriação e à formação dos conhecimentos matemáticos, o que implica pensar a relação Matemática-corpo em movimento como possibilidade de exploração em vários conteúdos. Isso posto, atividades e brincadeiras que envolvem o corpo em movimento podem propiciar experiências matemáticas desafiadoras, reflexivas e, sobretudo, significativas, fortalecendo, dessa maneira, a visão sistêmica do fazer pedagógico na Educação Infantil.

\section{ENCAMINHAMENTO METODOLÓGICO}

De abordagem qualitativa, do tipo exploratória e de natureza interpretativa, como esclarecem Bogdan e Biklen (1994), Gil (1987) e Lüdke e André (2018), a pesquisa que dá origem a este artigo foi realizada com três professoras atuantes na Educação Infantil. Com formação acadêmica em Pedagogia e experiência profissional entre 7 (sete) e 15 (quinze) anos, no período vigente da pesquisa, trabalhavam em escolas da rede municipal de Curitiba, PR, e cursavam Mestrado Profissional no Programa de Pós-Graduação em Educação: Teoria e Prática de Ensino, da Universidade Federal do Paraná (UFPR).

Os instrumentos de pesquisa para produção de dados reuniram roda de conversa e questionário estruturado. A roda de conversa versou sobre brincadeiras que envolvem o corpo em movimento e contou com a observação de imagens de brincadeiras que fazem parte do cotidiano escolar. Com isso, pôde-se verificar se as professoras percebem e como percebem os conhecimentos matemáticos quando fazem uso das brincadeiras. De igual modo, foi possível identificar suas percepções acerca do possível intercâmbio entre os dois campos de experiências promulgados pela BNCC, objeto desta pesquisa, a saber: "espaços, tempos, quantidades, relações e transformações" e "corpo, gestos e movimentos" (BRASIL, 2017). Já o questionário estruturado envolveu questões relativas à Educação Matemática na Educação Infantil e viabilizou o conhecimento do percurso formativo das professoras para uma análise mais efetiva e consistente da compreensão que fazem acerca da Educação Matemática na Educação Infantil.

A sistematização dos dados se deu pela aproximação à análise de conteúdo sob a perspectiva teórica de Bardin (2016), por meio da qual procedeu-se a organização e a 
classificação dos dados e, na sequência, a descrição e a interpretação dos mesmos. Importante destacar que, para a interpretação, os dados foram considerados em sua dimensão objetiva associada à subjetividade inerente aos pesquisadores e às professoras participantes.

As categorias de análise foram construídas a partir de elementos teóricos do pensamento complexo, sendo elas: conexidade-fragmentação; dialogicidade entre saberes; criatividade; o novo que brota; consciência matemática.

A roda de conversa foi realizada nas dependências da UFPR, haja vista que, nesse espaço, as participantes cursavam Mestrado Profissional. Por ser um ambiente comum, elas se sentiram a vontade e foram identificadas com a situação configurada. Desse modo, constituiu-se um cenário cuja atmosfera foi propícia a uma comunicação dialógica entre pesquisadores e participantes sobre contexto escolar, vivências e rotinas na Educação Infantil. Na oportunidade, peculiaridades foram reveladas e discutidas, argumentações foram efetivadas, como também ponderações propiciaram reflexões sobre a prática pedagógica de modo recursivo e prospectivo.

\section{RESULTADOS E DISCUSSÕES}

Os resultados aqui apresentados foram organizados a partir dos dois instrumentos metodológicos utilizados na pesquisa: questionário e roda de conversa. Com a empiria oriunda do questionário, destacam-se dois pontos estruturantes. $\mathrm{O}$ primeiro refere-se ao fato de as professoras reconhecerem, mesmo com visões diferentes, a Educação Matemática como componente curricular que se estrutura e se relaciona com o cotidiano escolar. O segundo diz respeito ao engajamento pedagógico delas ao demonstrarem comprometimento com a formação dos conhecimentos matemáticos, não julgando-os mais importantes que outros, mas identificando a Matemática como produto social.

Importante destacar também dois pontos que inspiram reflexões. São eles: 1) as professoras demonstraram uma maior preocupação em desenvolver um tipo de conhecimento, o numérico; 2) as professoras afirmaram que a formação inicial não valoriza o fazer pedagógico matemático na Educação Infantil. Ademais, salientaram que a estrutura curricular dos Cursos de Pedagogia que realizaram é centralizada no Ensino Fundamental, com pouca inserção de conteúdo teórico e prático voltado à Educação Infantil.

No que se refere ao ponto 1, acredita-se que, na Educação Infantil, é preciso estabelecer um equilíbrio entre os campos de estudo da Matemática. Além disso, o 
trabalho do professor pode contemplar ideias matemáticas em seus diferentes campos constitutivos, colocando em evidência, por exemplo, o campo geométrico, o campo algébrico ou o campo aritmético. Do mesmo modo, inferências, proporcionalidades, estatísticas e representações gráficas podem ser sinalizadas e desenvolvidas de forma lúdica para ampliação do universo matemático da criança. Para que isso tome forma, é necessário que os professores dominem conceitual e pedagogicamente a Matemática e saibam explorá-la nas diversas situações vivenciadas pelas crianças.

Quanto ao ponto 2, destaca-se a ausência de formação para a Educação Infantil, o que é preocupante no cenário educacional. Todavia, percebe-se um vínculo entre os dois pontos, uma vez que o fato de as professoras priorizarem o conhecimento aritmético indica a formação acadêmica insuficiente que receberam na graduação.

Esses fatores sinalizam que a formação inicial precisa ser repensada, de modo especial, em relação à Educação Matemática na Educação Infantil, pois tal formação pode contribuir para que os professores tenham condições adequadas e apropriadas para realizarem atividades que incorporem o desenvolvimento de ideias matemáticas de forma consciente.

Referentemente aos dados da roda de conversa, convém enfatizar que a discussão se deu a partir de elementos do pensamento complexo, fundamentado nas considerações acerca de Educação postuladas por Morin $(2000,2005,2011)$ e endossadas por Behrens (2017, 2019), Guérios (2002, 2019), Guérios e Modtkoski (2017), Moraes (2019) e Petraglia (2017), que apresentam a complexidade como matriz teórica em seus estudos.

Diante dos dados, constata-se que a categoria conexidade-fragmentação se configura na dicotomia entre a visão conexa das professoras, ao perceberem a importância das brincadeiras que envolvem o corpo em movimento para apropriação e formação dos conhecimentos matemáticos, e a visão fragmentada de compreensão da Educação Matemática na Educação Infantil, uma vez que manifestaram fragilidades conceituais acerca dos conhecimentos geométricos, aritméticos e algébricos.

Relevante considerar que corpo, movimento, brincadeiras e Matemática, na Educação Infantil, podem ser compreendidos de modo integrado e não fragmentado, compartimentado, descontextualizado. Mediante essa lógica, para existir uma visão conexa acerca da tríade Educação Matemática-brincadeiras-corpo em movimento, é necessário pensar na Matemática como um conjunto inter-retroativo ou sistêmico.

Outrossim, ao invés de uma sequência rígida de conteúdos disciplinares deslocados dos interesses das crianças, como afirmaram as professoras, a atividade na 
Educação Infantil tem como fulcro o trabalho que assegura os direitos de aprendizagem (BRASIL, 2017), os quais devem ser contemplados pelos campos de experiências que fomentam e favorecem a construção do conhecimento matemático.

Consoante Morin (2011), a complexidade preconiza o diálogo entre conhecimentos. De acordo com essa acepção, a categoria dialogicidade entre saberes construídos na interface dos campos de experiência preconizados pela $\mathrm{BNCC}$ contribuiu para identificar se, em suas práticas pedagógicas, as participantes relacionavam os campos de experiências "Espaços, tempos, quantidades, relações e transformações" e "Corpo gestos e movimentos".

Ao manifestarem que o trabalho na Educação Infantil deve assegurar os direitos de aprendizagem das crianças, diferentemente de uma sequência rígida de conteúdos disciplinares deslocados dos seus interesses, as professoras evocaram dizeres da BNCC (BRASIL, 2017). Nesse sentido, identificaram a proposta curricular como uma rede de diálogos entre saberes. Não obstante, evidenciou-se que a articulação entre os campos de experiências pode acontecer de modo mais conexo na prática se, efetivamente, houver um entendimento de que são campos relacionados aos objetivos propostos.

Em relação à categoria criatividade, as professoras demonstraram uma certa preocupação com o direito que as crianças têm de aprender matemática brincando, agindo, interagindo em diversas práticas pedagógicas com potencial criativo. Também deixaram transparecer disposição para criar ambientes que propiciem práticas pedagógicas dinâmicas e permitam às crianças desenvolver conhecimentos matemáticos imersos no universo cultural infantil, o que inclui brincadeiras que envolvem o corpo em movimento. Além disso, pôde-se comprovar que a adaptação criativa de brincadeiras é uma constante na prática cotidiana das participantes da pesquisa, a exemplo de uma "adaptação" feita por uma delas à tradicional Dança das Cadeiras que resultou na Dança das Cadeiras Inclusiva na qual nenhuma criança é excluída da brincadeira.

Foi possível identificar também movimentos desencadeadores de invenção pelas professoras, haja vista os projetos pedagógicos que propiciam às crianças o desenvolvimento de estratégias cognitivas durante as brincadeiras. Tais projetos, elaborados pelas professoras, permitem às crianças estabelecer planos, descobrir possibilidades e trocar ideias matemáticas com seus pares, o que vai ao encontro do entendimento de Ribeiro e Moraes (2014, p. 257):

A criatividade deve ser concebida e explorada na perspectiva de desenvolvermos uma consciência coletiva que promova a tolerância, valorize a 
independência de pensamento, preste atenção à diversidade, reconheça o esforço, premie a iniciativa, valorize positivamente as novas ideias.

Os movimentos desencadeadores de inovação e criatividade são basilares para a caracterização da categoria o novo que brota, inspirada na percepção de Morin (2011, p. 29) de que "o novo brota sem parar" e em Guérios (2002, p. 176) ao defender que "é preciso deixar o novo brotar".

Em virtude de a Educação Infantil lidar cotidianamente com o novo e constituirse em campo criativo fértil, em uma perspectiva complexa, a prática pedagógica deve proporcionar a cada criança condições para questionar, ponderar, argumentar, conjecturar, criar e testar hipóteses, estabelecer relações, resolver problemas e desenvolver o espírito investigativo. Nessa direção, o movimento pedagógico desenvolvido nas interfaces da tríade Educação Matemática-brincadeiras-corpo em movimento considera situações que emergem nas brincadeiras e, por deixá-las brotar, encorajam as crianças a pensar matematicamente.

Se anteriormente a tríade Educação Matemática-brincadeiras-corpo em movimento foi concebida como um sistema complexo cujos elementos se articulam entre si, com efeito, agora, é possível conceber as categorias "conexidade-fragmentação", "dialogocidade entre saberes", "criatividade" e "o novo que brota" também como um sistema em que cada uma é vinculada à outra. A dialogicidade entre saberes encontra ressonância na conexidade entre diferentes campos de conhecimentos e entre diferentes ideias que, por não estarem fragmentadas, permitem que o novo brote, ampliando, assim, o espectro para que a criatividade seja elemento potencializador da prática pedagógica.

A relação entre os sistemas possibilitou o emergir da categoria consciência matemática vinculada à intencionalidade pedagógica na movimentação da tríade Educação Matemática-brincadeiras-corpo em movimento na Educação Infantil. Ou seja, requer a internalização pelas professoras de que ideias matemáticas estão presentes em atividades que envolvem brincadeiras e que são potencializadas pelo corpo em movimento. Logo, brincadeiras convertem-se em atividade matemática e vice-versa.

Pelo exposto, destaca-se a importância das brincadeiras que envolvem o corpo em movimento para a apropriação e formação dos conhecimentos matemáticos na Educação Infantil. Assim sendo, o desenvolvimento de uma Consciência Matemática na prática pedagógica, por parte das professoras, pode contribuir para um exercício docente analítico e reflexivo na Educação Infantil. Essa consciência internalizada assegura às professoras identificar situações que podem ser exploradas matematicamente em 
diferentes, se não todas, atividades pertencentes ao universo lúdico que permeia a Educação Infantil. Nesse universo, incluem-se brincadeiras, jogos de diferentes naturezas, atividades rítmicas, danças, músicas, histórias cantadas, como também circunstâncias emergentes do cotidiano que, em uma perspectiva complexa, são agregadas e convertidas em situações de aprendizagem.

\section{CONSIDERAÇÕES FINAIS}

Neste estudo, procurou-se destacar a importância do fazer pedagógico matemático na Educação Infantil, ao discutir a tríade Educação Matemática-brincadeirascorpo em movimento. Ao analisar como as professoras participantes da pesquisa que originou este artigo percebem conhecimentos matemáticos presentes em brincadeiras, identificou-se que o corpo em movimento constitui alicerce para um fazer pedagógico integrativo na Educação Infantil.

As professoras evidenciaram a possibilidade de concepção da tríade Educação Matemática-brincadeiras-corpo em movimento como um sistema complexo pelo fato deste ser articulado e articulante. Articulado, pelos movimentos geradores de práticas interligadas pelos campos de experiência preconizados pela BNCC. Articulantes, pelo estímulo à criatividade decorrente da conexidade interna ao sistema concebido no qual brincadeira e corpo em movimento, interligando dialogicamente seus saberes componentes, propiciam práticas pedagógicas para o desenvolvimento de ideias matemáticas.

No decorrer da atividade metodológica de produção e análise de dados, constatou-se que as professoras vivenciaram um processo de ressignificação de seus conhecimentos em relação à formação e à apropriação dos conhecimentos matemáticos por meio das brincadeiras que envolvem o corpo em movimento na Educação Infantil. A análise revelou, portanto, que elas reconhecem a importância dessas brincadeiras para a formação de conhecimentos matemáticos na Educação Infantil.

Apesar de as professoras demonstrarem uma visão fragmentada no que tange à compreensão da Educação Matemática na Educação Infantil, validaram a possibilidade de construção de uma complexidade educativa que, segundo Barbosa (2020, p. 36), "vislumbra unir saberes, transformar práticas educativas; valorizar experiências significativas; fortalecer ações didáticas criativas; dinamizar a relação ensinoaprendizagem; associar conhecimentos; produzir conexões inteligíveis”. Em outras palavras, uma complexidade educativa que considera a multidimensionalidade dos 
fenômenos constitutivos da prática pedagógica e, por considerar a dinamicidade uma característica do cotidiano escolar, possibilita o desenvolvimento de práticas conexas e integradas de modo não linear.

Em síntese, os resultados permitem refletir sobre a relevância da Educação Matemática na Educação Infantil por meio das brincadeiras, legitimando a importância do corpo em movimento como alicerce para o desenvolvimento infantil.

\section{REFERÊNCIAS}

BARBOSA, P. R. D. Conhecimentos matemáticos presentes em brincadeiras da educação infantil que envolvem o corpo em movimento. 2020. 120 f. Dissertação (Mestrado em Educação: Teoria e Prática de Ensino) - Universidade Federal do Paraná, Curitiba, PR, 2020. Disponível em:

https://www.prppg.ufpr.br/siga/visitante/trabalhoConclusaoWS?idpessoal=57247\&idpro grama $=40001016080 \mathrm{P} 7 \&$ anobase $=2020 \& i d t c=70$. Acesso em: 08 nov. 2020 .

BARDIN, L. Análise de conteúdo. São Paulo: Edições 70, 2016.

BEHRENS, M. A. Paradigma da complexidade e transdisciplinaridade numa visão transformadora. In: GUÉRIOS, E. C.; PISKE, F. H. R.; SOEK, A. M.; SILVA, E. J. Complexidade e educação: diálogos epistemológicos transformadores. Curitiba: CRV, 2017. p. 81-96.

BEHRENS, M. A.; PRIGOL, E. L. Prática docente: das teorias críticas à teoria da complexidade. In: SÁ, R. A.; BEHRENS, M. A. Teoria da complexidade: contribuições epistemológicas e metodológicas para uma pedagogia complexa. Curitiba: Appris, 2019. p. 65-86.

BOGDAN, R. C.; BIKLEN, S. K. Investigação qualitativa em educação: uma introdução à teoria e aos métodos. Portugal: Porto Editora, 1994.

BRASIL. Ministério da Educação. Base Nacional Comum Curricular. Brasília: MEC/CONSED/UNDIME, 2017. Disponível em:

http://www.basenacionalcomum.mec.gov.br/. Acesso em: 20 maio 2020.

CAMARGO, G. G. de; BAGNE, J.; BOLOGNANI, M. S. F.; COLETTI, S.

Desenvolvimento do pensamento algébrico com crianças?... possibilidades de práticas na educação infantil. In: NACARATO, A. M.; CUSTÓDIO, I. A. O Desenvolvimento do Pensamento Algébrico na Educação Básica: Compartilhando Propostas de Sala de Aula com o Professor que Ensina (Ensinará) Matemática. Brasília: Sociedade Brasileira de Educação Matemática, 2018. p. 25-70 E-book. Disponível em:

http://www.sbembrasil.org.br/files/ebook_desenv.pdf. Acesso em: 20 maio 2020.

CALVACANTE, N. F. M. Problematizações a partir de situações emergentes do cotidiano: compreensões e possibilidades envolvendo relações quantitativas, medidas, formas e orientações espaço temporais em turmas de crianças de quatro anos. 2015. 161f. Dissertação (Mestrado em Educação) - Centro de Educação e Ciências Humanas, Universidade Federal de São Carlos, SP, 2015. 
DA COSTA, L. P.; VERRENGIA, S. R. D.; PAVANELLO, R. M.; OLIVEIRA, L. L. A. de; CARLI, F. A. R. de.; TRONDOLI, A. J. P. C. A geometria na educação infantil: O quê? Por quê? Como? Curitiba: CRV, 2018.

DUHALDE, M. E.; CUBERES, M. T. G. Encontros iniciais com a matemática: contribuições à educação infantil. Porto Alegre: Artes Médicas, 1998.

FREIRE, J. B. Educação de corpo inteiro: teoria e prática da educação básica. São Paulo: Scipione, 1989.

GALLAHUE, D. L.; OZMUN, J. C. Compreendendo o desenvolvimento motor: bebês, crianças, adolescentes e adultos. São Paulo: Phorte, 2005.

GARANHANI, M. C. Concepções e práticas pedagógicas de educadoras da pequena infância: os saberes sobre o movimento corporal da criança. 2004. 155 f. Tese (Doutorado em Educação - Psicologia da Educação) - Pontifícia Universidade Católica de São Paulo, São Paulo, 2004. Disponível em: https://tede2.pucsp.br/handle/handle/16412. Acesso em: 21 maio 2020.

GARANHANI, M. C. O movimento da criança no contexto da educação infantil: reflexões com base nos estudos de Wallon. Revista Cotrapontos, Itajaí, v. 5, n. 1, p. 8193, 2005. Disponível em: https://siaiap32.univali.br/seer/index.php/rc/article/view/807. Acesso em: 21 maio 2020.

GIL, A. C. Métodos e técnicas de pesquisa social. São Paulo: Atlas, 1987.

GUEDES, M. H. S. Oficina da brincadeira. Rio de Janeiro: Sprint, 1998.

GUÉRIOS, E. C. Espaços oficiais e intersticiais da formação docente: histórias de um grupo de professores na área de ciências e matemática 2002. 234 f. Tese (Doutorado em Educação) - Faculdade de Educação, Universidade Estadual de Campinas, São Paulo, 2002. Disponível em:

http://repositorio.unicamp.br/bitstream/REPOSIP/253667/1/Guerios_EttieneCordeiro_D. pdfAcesso em: 20 maio 2020.

GUÉRIOS, E. Contribuições do pensamento complexo para a formação de professores em uma perspectiva transdisciplinar. In: SÁ, R. A.; BEHRENS, M. A. Teoria da complexidade: contribuições epistemológicas e metodológicas para uma pedagogia complexa. Curitiba: Appris, 2019. p. 223-236.

GUÉRIOS, E. C.; MODTKOSKI, H. M. Conexões entre Gaston Bachelard, Edgar Morin e o pensamento complexo. In: GUÉRIOS, E. C.; PISKE, F. H. R.; SOEK, A. M.; SILVA, E. J. Complexidade e educação: diálogos epistemológicos transformadores. Curitiba: CRV, 2017. p. 115-136.

KAMII, C. A criança e o número: implicações educacionais da teoria de Piaget para a atuação junto a escolares de 4 a 6 anos. Campinas, SP: Papirus, 1984.

KAMII, C. Reinventando a aritmética: implicações da teoria de Piaget. 4. ed. Campinas, SP: Papirus, 1991.

KAMII, C. Aritmética: novas perspectivas: implicações da teoria de Piaget. 4. ed. Campinas, SP: Papirus, 1995.

KAMII, C. Crianças pequenas reinventam a aritmética: implicações da teoria de Piaget. 2. ed. Porto Alegre: Artes Médicas, 2002. 
KAMII, C. Crianças pequenas continuam reinventando a aritmética: implicações da teoria de Piaget. 2. ed. Porto Alegre: Artes Médicas, 2005.

KAMII, C. Jogos em grupo na educação infantil: implicações da teoria de Piaget. Porto Alegre: Artes Médicas, 2009.

LE BOULCH, J. O desenvolvimento psicomotor: do nascimento aos 6 anos. Porto Alegre: Artes Médicas, 1982.

LE BOULCH, J. A educação do movimento: a psiconética na idade escolar. Porto Alegre: Artes Médicas, 1983.

LÜDKE, M.; ANDRÉ, M. Pesquisa em educação: abordagens qualitativas. 2. ed. Rio de Janeiro: E.P.U., 2018.

MORAES, M. C. Questões curriculares contemporâneas no âmbito da complexidade e da transdisciplinaridade. In: SÁ, R. A. BEHRENS, M. A. Teoria da complexidade: contribuições epistemológicas e metodológicas para uma pedagogia complexa. Curitiba: Appris, 2019. p. 99-138.

MORIN, E. A cabeça bem feita: repensar a reforma, reformar o pensamento. Rio de Janeiro: Bertrand Brasil, 2000.

MORIN, E. Ciência com consciência. 8. ed. Rio de Janeiro: Bertrand, 2005.

MORIN, E. Os sete saberes necessários à educação do futuro. 4. ed. Brasília, DF: Cortez, 2011.

MORIN, E. Ensinar a viver: manifesto para mudar a educação. Porto Alegre: Sulina, 2015.

NACARATO, A. M.; CUSTÓDIO, I. A. O Desenvolvimento do Pensamento Algébrico na Educação Básica: Compartilhando Propostas de Sala de Aula com o Professor que Ensina (Ensinará) Matemática. Brasília, DF: Sociedade Brasileira de Educação Matemática, 2018. E-book. Disponível em: http://www.sbembrasil.org.br/files/ebook_desenv.pdf. Acesso em: 20 maio 2020.

OLIVEIRA, D. S. O Brincar e as concepções de conceitos matemáticos de crianças de 5 anos. 2017. 166 f. Dissertação (Mestrado em Psicologia) - Universidade de Brasília, Brasília, DF, 2017. Disponível em: https://repositorio.unb.br/bitstream/10482/23462/1/2017_DeniseSoaresOliveira.pdf. Acesso em: 08 abr. 2020.

PETRAGLIA, I.; VASCONCELOS, M. A. F. C. Um pensamento complexo para o conhecimento e a educação. In: GUÉRIOS, E. C.; PISKE, F. H. R.; SOEK, A. M.; SILVA, E. J. Complexidade e educação: diálogos epistemológicos transformadores. Curitiba: CRV, 2017. p. 67-80.

RIBEIRO, O.; MORAES, M. C. Criatividade em uma perspectiva transdisciplinar. Brasília, DF: Liber Livro/Unesco, 2014.

SILVA, S. R. As brincadeiras e as noções espaciais na Educação Infantil. 2016. 173f. Dissertação (Mestrado em Educação) - Instituto de Educação, Universidade Federal de Mato Grosso, Cuiabá, 2016.

SMOLE, K. C. S.; DINIZ, M. I.; CÂNDIDO, P. Brincadeiras infantis nas aulas de matemática. Porto Alegre: Artes Médicas, 2000. 
ZOGAIB, S. D. Sentido espacial de crianças na educação infantil: entre mapas, gestos e falas. 2019. 249 f. Tese (Doutorado em Educação) - Centro de Educação, Universidade Federal do Espírito Santo, 2019. Disponível em:

http://repositorio.ufes.br/bitstream/10/11099/1/tese_13241_SIMONE\%20DAMM\%20Z OGAIB.pdf. Acesso em: 08 abr. 2020. 